EGU2020-9404

https://doi.org/10.5194/egusphere-egu2020-9404

EGU General Assembly 2020

(c) Author(s) 2020. This work is distributed under

the Creative Commons Attribution 4.0 License.

\title{
SOC modelling and cropping system managements in contrasting climatic conditions
}

\author{
Marco Acutis ${ }^{1}$, Elena Valkama ${ }^{2}$, Gulya Kunypiyaeva ${ }^{3}$, Muratbek Karabayev ${ }^{4}$, Rauan Zhapayev ${ }^{5}$, \\ Erbol Zhusupbekov ${ }^{5}$, Alessia Perego ${ }^{1}$, Calogero Schillaci ${ }^{1}$, Dario Sacco ${ }^{6}$, Barbara Moretti ${ }^{6}$, and Carlo \\ Grignani ${ }^{6}$ \\ ${ }^{1}$ University of Milano, Department of Agricultural and Environmental Sciences - Production, Landscape, Agroenergy, Milano, \\ Italy (marco.acutis@unimi.it; alessia.perego@unimi.it; calogero.schillaci@unimi.it) \\ ${ }^{2}$ Natural Resources Institute Finland (Luke), Bioeconomy and environment, Jokioinen, Finland (elena.valkama@luke.fi) \\ ${ }^{3}$ CIMMYT-Kazakhstan, Almaty, Kazakhstan (kunypiyaeva_gulya@mail.ru) \\ ${ }^{4}$ CIMMYT-Kazakhstan, Nur-Sultan, Kazakhstan (muratbek.karabayev@gmail.com) \\ ${ }^{5}$ Kazakh Research Institute of agriculture and Plant Growing, Almalybak, Kazakhstan (r.zhapayev@mail.ru; \\ erbol.zhusupbekov@mail.ru) \\ ${ }^{6}$ Environmental Agronomy, Department of Agricultural, Forest and Food Sciences, University of Torino, Italy \\ (dario.sacco@unito.it; barbara.moretti@unito.it; carlo.grignani@unito.it
}

Conservation agriculture (CA) involves complex and interactive processes that ultimately determine soil C storage, making it difficult to identify clear patterns, particularly, when the results originate from many experimental studies. To solve these problems, we used the ARMOSA processbased crop model to simulate the contribution of different CA components (minimum soil disturbance, permanent soil cover with crop residues and/or cover crops, and diversification of plant species) to soil organic carbon (SOC) sequestration at 0-30 cm soil depth and to compare it with SOC evolution under conventional agricultural practices. We simulated SOC changes in two sites located in Central Asia (Almalybak, Kazakhstan) and Southern Europe (Lombriasco, Italy), which have contrasting soils, organic carbon contents, climates, crops and management intensity. Simulations were carried out for the current (1998-2017) and future climatic scenarios (period 2020-2040, scenario Representative Concentration Pathway 6.0).

Five cropping systems were simulated: conventional systems under ploughing at 25-30 cm with monoculture and residues removed (Conv-R) or residues retained (Conv+R); no-tillage (NT) with residue retained and crop monocultures; $C A$ and $C A$ with a cover crop, Italian ryegrass $(C A+C C)$. In Conv-R, Conv+R and NT, the simulated monocultures were spring barley in Almalybak and maize in Lombriasco. In CA and CA+CC, crop rotations were winter wheat - winter wheat - spring barley chickpea in Almalybak; maize - winter wheat - soybean in Lombriasco, together with Italian ryegrass in the $+\mathrm{CC}$ options.

In Lombriasco, conventional systems led to SOC decline of 170-350 $\mathrm{kg} \mathrm{ha}^{-1} \mathrm{yr}^{-1}$, whereas, NT and CA prevented the decline and kept it on the slightly positive level under both climate scenarios. A low rate of SOC increase most likely stems from, in addition to climates, the low silt-clay fraction 
(34\%), and thus, more vulnerable to mineralization and decay.

In Almalybak, SOC loss in conventional systems was 480-560 $\mathrm{kg} \mathrm{ha}^{-1} \mathrm{yr}^{-1}$ under current climate, and NT prevented the loss only under current climate, but not under the future climate scenario. In contrast, CA allowed for the annual C sequestration of $300 \mathrm{~kg} \mathrm{ha}^{-1}$ and up to $620 \mathrm{~kg} \mathrm{ha}^{-1}$ with cover crops. Under the future climate scenario, the model predicted somewhat less $\mathrm{C}$ sequestration under CA, probably, due to the reduction of residue biomass. Particularly, in Southern Kazakhstan, $\mathrm{CA}$ has the largest potential for $\mathrm{C}$ sequestration under both climate scenarios, twice exceeding the objectives of the " 4 per 1000 " initiative. This initiative claims that an annual growth rate of $0.4 \%$ in the soil carbon stocks, or $4 \%$ per year, in the first $30-40 \mathrm{~cm}$ of soil, would significantly reduce the $\mathrm{CO}_{2}$ concentration in the atmosphere related to human activities. 